and administration (Dr. Allott), agriculture (Mr. Silk), music (The Rev. A. M. Jones), and trade unions (Mr. W. Hood). The last day of the course was devoted to a consideration of various aspects of investment and technical aid, when papers were read by Mr. M. T. Mbu; Commissioner for Nigeria in the United Kingdom, Mr. A. D. Knox, and Dr. E. Hallett.

\title{
The Garessa Museum, Mogadishu
}

THE Garessa, now the national museum of Somalia, was opened in 1934 as the museum for what was then the Italian colony; it is housed in a magnificent fort built in the second half of the nineteenth century by the Sultan of Zanzibar as the seat of his government in Somalia. The museum possesses a wide variety of collections and includes a reading-room and an extensive modern library which contains many of the more important works on Somali ethnography and sociology, a fairly wide selection of publications on the former Italian African colonies and on Africa in general, as well as books of a more general nature.

Besides geological, zoological, numismatic, and other important collections, the Garessa contains possibly the finest collection of objects of ethnographic interest illustrating Somali culture. These include examples from the pre-Somali Negro riverain peoples of Somalia and from the other non-Somali minority communities. A valuable collection of historical manuscripts and documents includes many of the treaties and agreements made by local chiefs with the early Italian colonizers. There is also a considerable body of Arabic manuscripts, some religious works by Somali sheikhs, and a mass of correspondence between famous Somali personalities and the early Italian Administration. All these are of considerable interest not only for the local history of Mogadishu and the other ancient cities of southern Somalia, Merca, Brava, and Kismayu, but also for the general history of the East African coast. The interior courtyard of the Garessa is adorned with inscriptions from the old mosques of southern Somalia (mainly Mogadishu) some of which date from the eighth century, one being in Cufic characters. While it is true that many of the historical items in the museum have already been drawn upon in publications, mainly by Italian scholars, the museum still has much as yet unexploited material to offer to various branches of scholarship. It certainly deserves to be more widely known and visited. Although it is now out of date, some idea of the richness of the collections may be gathered from the 1934 catalogue (Museo della Garessa, Catalogo, Mogadishu, 1934, pp. 177, 109 Pp. illus.). A new catalogue and a rearrangement of the collections are in progress under the Garessa's enthusiastic new Director, Dr. S. Appolonio. The museum is also fortunate in having on its staff Yaasiin Ismaan Kenadiid, the son of Ismaan Yuusuf, inventor of the well-known 'Somali writing' (or Ismaaniya), an acknowledged authority on Somali folk-literature who has been trained in phonetics in Italy.

A recent venture is the publication of the bi-monthly periodical Somalia d'Oggi, edited from the museum, of which the first two numbers have now appeared. It is not a technical journal for specialists and is naturally largely devoted to the discussion of developments in the nascent state of Somalia and the surrounding territories. It does, however, devote some space to ethnographic and historical subjects. The second number, for example, contains some six articles of this kind, of interest to students of Somali ethnology. Somalia d'Oggi should provide a valuable means of recording local information which might otherwise never be published. It is to be hoped that the Garessa Museum may be able to make some practical contribution to research on a number of topics which urgently need investigation. Sociological and ethnographic information on the Somali populations of Southern Somalia is still very imperfect and there is need for a study of the non-Somali Bantu riverain communities which are progressively losing their identity in modern Somalia. 